\title{
HUBUNGAN FAKTOR LINGKUNGAN DENGAN KEJADIAN DIARE PADA BALITA DI DESA SUMBANG KECAMATAN SUMBANG KABUPATEN BANYUMAS TAHUN 2016
}

\author{
Tri Asih Widiastuti*), Asep Tata Gunawan**), Yulianto***) \\ Jurusan Kesehatan Lingkungan, Politeknik Kesehatan Kemenkes Semarang \\ Jl. Raya Baturraden KM 12 Purwokerto, Indonesia
}

\begin{abstract}
Abstrak
Diare merupakan salah satu masalah kesehatan masyarakat di Indonesia, hal ini dikarenakan masih tingginya angka kesakitan diare yang menimbulkan kematian terutama pada balita. Faktor lingkungan yang buruk dapat menyebabkan seorang balita terkena diare. Penelitian ini bertujuan untuk mengetahui hubungan faktor lingkungan dengan kejadian diare pada balita di desa Sumbang, Kecamatan Sumbang, Kabupaten Banyumas. Metode yang digunakan dalam penelitian ini adalah metode analitik inferensial dengan pendekatan cese control. Semua populasi menjadi obyek dalam penelitian ini. Populasi dalam penelitian ini dibagi menjadi 2 yaitu populasi kasus dan populasi control. Populasi kasus adalah balita diare yang berobat ke Puskesmas 1 Sumbang pada bulan Maret-Mei 2016 sejumlah 21 penderita, sedangkan populasi kontrol adalah balita bukan penderita diare yang berobat pada bulan Maret-Mei 2016 sejumlah 21 penderita. Analisis dilakukan dengan uji Chi Square Hasil penelitian ini menunjukan bahwa ada hubungan antara faktor lingkungan yang meliputi sarana air bersih $(p=0,001, O R=13,6)$, jamban $(p=0,013$, OR=6,4), penyimpanan makanan $(p=0,01, O R=8)$, penyediaan air minum $(p=0,000, O R=23,75)$, cucitangan $(p=0,029=, O R=5,2)$ dan pembuangan tinja $(p=0,012, O R=6,906)$ dengan kejadian diare pada balita di desa Sumbang. Ada pengaruh secara bersama-sama antara sarana air bersih $(p=0,006)$ dan penyediaan air minum $(p=0,002)$ terhadap kejadian diare pada balita di desa Sumbang. Sebagai upaya pencegahan terjadinya diare pada balita disarankan kepada masyarakat untuk memperbaiki kondisi fisik sumur gali, menggunakan jamban saniter sebagai sarana buang air besar, memperhatikan penyimpanan makanan dan penyediaan air minum yang baik serta membiasakan cuci tangan pakai sabun.
\end{abstract}

\section{Kata Kunci: Diare, Balita, Kesehatan Lingkungan}

\begin{abstract}
Diarrhea is one of public health problem in Indonesia, this is caused of the high of diarrhea morbidity rate that can cause infant death. Bad environmental factors can cause the infant to infected diarrhea. The purpose of this research is to know the relationship of environmental factors with diarrhea incidence at the infant in Sumbang Village, Sumbang Dictrict, Banyumas Regency. The method that is used on this research is analytical infrential method with the case control approachment. All of population be object on this research. The case population is infant who infected diarrhea that is treated at 1st Sumbang Health Center on MarchMay 2016 as many as 21 patients, while the control population is the infant that is not diarrhea patient who treated at March-May 2016 as many as 21 patients. The analysis was performed by chi square test. The result of this research indicate that there are any relationship between environmental factors include water supply $(p=0,001, O R=13,6)$, latrine $(p=0,013$, OR=6,4), food storage $(p=0,001$, OR=8), water drinking supply $(p=0,000, O R=23,75)$, hand washing $(p=0,029, O R=5,2)$ and excreta disposal $(p=0,012, O R=6,906)$ with diarrhea incidence at the infant. There are any together influence between water supply $(p=0,006)$ and water drinking supply $(p=0,002)$ to diarrhea incidence at the infant in Sumbang village. As the prevention efforts to infant diarrrhea it can be adviced to improve the physical condition of wells, use sanitary latrine as a means to defecate, pay attention to food storage and good water drinking supply and habituate to hand washing with the soap.
\end{abstract}

\section{Keyword: diarrhea, toddler, environment health}

\footnotetext{
*) E mail: triasihwidiastuti@yahoo.com

**) E mail : aseptatagunawan@yahoo.co.id

***) E mail: yulianto_61@yahoo.com
} 


\section{Pendahuluan}

Diare merupakan penyakit endemis di Indonesia dan merupakan penyakit potensial kejadian luar biasa (KLB) yang sering disertai dengan kematian. Menurut hasil Riskesdas 2007, diare merupakan penyebab kematian nomor satu pada bayi $(31,4 \%)$ dan pada balita $(25,2 \%)$. Sedangkan pada golongan semua umur merupakan penyebab kematian yang keempat $(13,2 \%)$. Dalam kajian morbiditas diare tahun 2012, angka kesakitan diare pada semua umur sebesar 214 per 1000 penduduk dan angka kesakitan diare pada balita 900 per 1000 penduduk (Kemenkes RI, 2014, h.147).

Diare merupakan salah satu penyakit yang berbasis lingkungan Cara penularan penyakit diare melalui fecal-oral yaitu melalui makanan atau minuman yang tercemar kuman atau kontak langsung tangan penderita atau tidak langsung melauli lalat. Faktor yang menyebabkan terjadinya diare adalah faktor lingkungan dan perilaku. (Ditjen PP \& PL, 2011b, h.14). Dua faktor lingkunganyang dominan, yaitu sarana air bersih dan pembuangan tinja. Kedua faktor ini akan berinteraksi dengan perilaku manusia. Apabila faktor lingkungan tidak sehat karena tercemar kuman diare serta berakumulasi dengan perilaku manusia yang tidak sehat pula, yaitu melalui makanan dan minuman, maka dapat menimbulkan kejadian penyakit diare. (Departemen Kesehatan R.I, 2002, h. 12).

Beberapa perilaku dapat menyebabkan penyebaran kuman dan meningkatkan resiko terjadinya diare, diantaranya adalah perilaku

penyimpanan makanan pada suhu kamar, menggunakan air minum yang tercemar, tidak cuci tangan dan tidak membuang tinja dengan benar (Ditjen PP \& PL, 2011a, h.51), Hasil penelitian menunjukan ada hubungan antara indikator perilaku menggunakan air bersih dan air minum $(\mathrm{p}=0,003$, $\alpha=0,05)$, perilaku menggunakan jamban $(\mathrm{p}=0,002$, $\alpha=0,05)$ dan perilaku mencuci tangan $(\mathrm{p}=0,001$, $\alpha=0,005)$ dengan kejadian diare.( Bhakti Rochman Tri Bintaro, 2010).

Kasus diare di Kabupaten Banyumas dari tahun ketahun masih tinggi dibanding dengan penyakit lainnya. Jumlah kasus diare Kabupaten Banyumas tahun 2014 adalah 42.496 (DKK Kab. Banyumas, 2015, h.17). Jumlah penderita diare di wilayah kerja Puskesmas 1 Sumbang masuk kedalam 10 besar jumlah penderita penyakit terbanyak dan selama 3 tahun terakhir dari tahun 2013-2015 mengalami peningkatan dari 770 kasus diare di tahun 2013, 868 kasus di tahun 2014 dan meningkat lagi menjadi 1045 kasus di tahun 2015. Jumlah penderita diare tertinggi tahun 2015 di wilayah kerja Puskesmas 1 Sumbang adalah desa Sumbang sebesar 180 kasus dengan jumlah terbanyak pada balita 73 penderita (40,6\%). (Puskesmas 1 Sumbang, 2014-2016).

Disamping tingginya kasus diare, desa Sumbang juga memiliki akses jamban terendah yaitu 28,03\%. Melihat tingginya kasus diare pada balita dan rendahnya akses penduduk terhadap jamban di desa Sumbang, penulis tertarik untuk melakukan penelitian di desa tersebut yaitu dengan judul penelitian "Hubungan Faktor Lingkungan dengan Kejadian Diare Pada Balita Di Desa Sumbang Kecamatan Sumbang Kabupaten Banyumas Tahun 2016".

\section{Bahan dan Metode}

Jenis penelitian ini merupakan Analisis Inferensial (uji hipotesis) dengan pendekatan Case Contrrol untuk mengetahui hubungan faktor lingkungan dengan kejadian diare pada balita di Desa Sumbang, Kecamatan Sumbang, Kabupaten Banyumas. Semua populasi menjadi obyek dalam penelitian ini. Pulasi dalam penelitian ini dibagi menjadi 2 yaitu populasi kasus dan populasi kontrol. Populasi kasus adalah balita penderita diare yang berasal dari Desa Sumbang yang berobat di Puskesmas I Sumbang pada bulan Maret-Mei 2016 sejumlah 21 penderita. Populasi kontrol adalah balita bukan penderita diare yang berasal dari Desa Sumbang dan berobat di Puskesmas I Sumbang pada bulan Maret-Mei sejumlah 21 penderita, dengan kriteria berjenis kelamin sama, umur sama atau selisih maksimal 6 bulan, alamat sama atau masih dalam wilayah satu RW, berobat di hari yang sama atau maksimal selisih 2 hari.

Variabel dalam penelitian ini adalah variabel bebas dan variabel terikat. Variabel bebas meliputi sarana air bersih, sarana jamban, penyimpanan makanan, penyediaan air minum, cuci tangan dan pembuangan tinja. Variabel terikat adalah kejadian diare pada balita di Desa Sumbang, Kecamatan Sumbang, Kabupaten Banyumas.

Pengumpulan data dilakukan dengan observasi dengan menggunakan check list dan wawancara dengan kuesioner. Setelah pengumpulan data dilakukan editing, coding, transferring, tabulating dan kemudian dianalisis.

Analisis yang digunakan dalam penelitian ini adalah analisis univariat, bivariat dan multivariate. Analisis univariat dilakukan untuk menggambarkan atau mendeskripsikan masing-masing variabel. Analisis bivariat untuk mencari hubungan antara variabel bebas dengan variabel terikat dengan Uji Chi Square dan Odd's Ratio. Analisis Multivariat untuk melihat faktor risiko paling besar terhadap kejadian diare pada balita di Desa Sumbang dengan menggunakan regresi logistik.

\section{Hasil Dan Pembahasan}

\section{a. Karakteristik Responden}


Tabel 1. Distribuasi Frekuensi Karakteristik Responden Berdasarkan Umur Di Desa Sumbang Kecamatan Sumbang Kabupaten Banyumas Tahun 2016

\begin{tabular}{cccr}
\hline No & $\begin{array}{c}\text { Umur } \\
\text { Responden } \\
\text { (Tahun) }\end{array}$ & Frekuensi & $\begin{array}{c}\text { Persentase } \\
(\%)\end{array}$ \\
\hline 1 & $20-25$ & 5 & 11,9 \\
2 & $26-30$ & 9 & 21,4 \\
3 & $31-35$ & 11 & 26,2 \\
4 & $36-40$ & 9 & 21,4 \\
5 & $41-45$ & 3 & 7,1 \\
6 & $46-50$ & 2 & 4,8 \\
7 & $51-55$ & 3 & 7,1 \\
\hline & Jumlah & 42 & 100,0 \\
\hline
\end{tabular}

Tabel 2. Distribuasi Frekuensi Karakteristik Balita Berdasarkan Umur Di Desa Sumbang Kecamatan Sumbang Kabupaten Banyumas Tahun 2016

\begin{tabular}{cccc}
\hline No & $\begin{array}{c}\text { Umur Balita } \\
\text { (bulan) }\end{array}$ & Frekuensi & $\begin{array}{c}\text { Persentase } \\
(\%)\end{array}$ \\
\hline 1 & $13-24$ & 8 & 19,0 \\
2 & $25-36$ & 15 & 35,7 \\
3 & $37-48$ & 5 & 11,9 \\
4 & $49-60$ & 14 & 33,3 \\
\hline & Jumlah & 42 & 100,0 \\
\hline
\end{tabular}

b. Hubungan Faktor Lingkungan Dengan

Tabel 3: Hubungan Sarana Air Bersih Dengan Kejadian Diare Pada Balita Di Desa Sumbang Kecamatan Sumbang Kabupaten Banyumas Tahun 2016

\begin{tabular}{|c|c|c|c|c|c|c|c|}
\hline \multirow{3}{*}{ Sarana Air Bersih } & \multicolumn{4}{|c|}{ Kejadian Diare pada Balita } & \multirow{3}{*}{$\begin{array}{c}\text { Nilai } \\
\text { P }\end{array}$} & \multirow{3}{*}{ OR } & \multirow{3}{*}{$95 \% \mathrm{CI}$} \\
\hline & \multicolumn{2}{|c|}{ Diare } & \multicolumn{2}{|c|}{ Tidak Diare } & & & \\
\hline & $\mathrm{n}$ & $(\%)$ & $\mathrm{n}$ & $(\%)$ & & & \\
\hline Tidak memenuhi syarat & 16 & 76,2 & 4 & 19 & 0001 & 136 & $3091-50831$ \\
\hline Memenuhi syarat & 5 & 23,8 & 17 & 81 & 0,001 & 15,0 & $5,091-59,051$ \\
\hline Total & 21 & 100,0 & 21 & 100 & & & \\
\hline
\end{tabular}

Tabel 4. Hubungan Jamban Dengan Kejadian Diare Pada Balita Di Desa Sumbang Kecamatan Sumbang Kabupaten Banyumas Tahun 2016

\begin{tabular}{|c|c|c|c|c|c|c|c|}
\hline \multirow{3}{*}{ Jamban } & \multicolumn{4}{|c|}{ Kejadian Diare pada Balita } & \multirow{3}{*}{$\begin{array}{c}\text { Nilai } \\
\mathrm{P}\end{array}$} & \multirow{3}{*}{ OR } & \multirow{3}{*}{$95 \% \mathrm{CI}$} \\
\hline & \multicolumn{2}{|c|}{ Diare } & \multicolumn{2}{|c|}{ Tidak Diare } & & & \\
\hline & $\mathrm{n}$ & $(\%)$ & $\mathrm{n}$ & $(\%)$ & & & \\
\hline Tidak memenuhi syarat & 16 & 76,2 & 7 & 33,3 & 0013 & 64 & $1654-24770$ \\
\hline Memenuhi syarat & 5 & 23,8 & 14 & 66,7 & 0,015 & 0,4 & $1,034-24,1 / 10$ \\
\hline Total & 21 & 100,0 & 21 & 100,0 & & & \\
\hline
\end{tabular}

Tabel 5. Hubungan Penyimpanan Makanan Dengan Kejadian Diare Pada Balita Di Desa Sumbang Kecamatan Sumbang Kabupaten Banyumas Tahun 2016

\begin{tabular}{|c|c|c|c|c|c|c|c|}
\hline \multirow{3}{*}{ Penyimpanan Makanan } & \multicolumn{4}{|c|}{ Kejadian Diare pada Balita } & \multirow{3}{*}{$\begin{array}{c}\text { Nilai } \\
\mathrm{p}\end{array}$} & \multirow{3}{*}{ OR } & \multirow{3}{*}{$95 \% \mathrm{CI}$} \\
\hline & \multicolumn{2}{|c|}{ Diare } & \multicolumn{2}{|c|}{ Tidak Diare } & & & \\
\hline & $\mathrm{n}$ & $(\%)$ & $\mathrm{n}$ & $(\%)$ & & & \\
\hline Tidak baik & 18 & 85,7 & 9 & 42,9 & \multirow{2}{*}{0.010} & \multirow{2}{*}{8.000} & \multirow{2}{*}{$1.790-35.744$} \\
\hline Baik & 3 & 14,3 & 12 & 57,1 & & & \\
\hline Total & 21 & 100 & 21 & 100,0 & & & \\
\hline
\end{tabular}

Tabel 4.14: Hubungan Penyediaan Air Minum dengan Kejadian Diare Pada Balita Di Desa Sumbang Kecamatan Sumbang Kabupaten Banyumas Tahun 2016

\begin{tabular}{|c|c|c|c|c|c|c|c|}
\hline \multirow{3}{*}{ Penyediaan Air Minum } & \multicolumn{4}{|c|}{ Kejadian Diare pada Balita } & \multirow{3}{*}{$\begin{array}{c}\text { Nilai } \\
\text { P }\end{array}$} & \multirow{3}{*}{$\mathrm{OR}$} & \multirow{3}{*}{$95 \% \mathrm{CI}$} \\
\hline & \multicolumn{2}{|c|}{ Diare } & \multicolumn{2}{|c|}{ Tidak Diare } & & & \\
\hline & $\mathrm{n}$ & $(\%)$ & $\mathrm{n}$ & $(\%)$ & & & \\
\hline Tidak baik & 15 & 71,4 & 2 & 9,5 & \multirow[b]{2}{*}{0,000} & \multirow[b]{2}{*}{23,750} & \multirow[b]{2}{*}{$4,179-134,987$} \\
\hline Baik & 6 & 28,6 & 9 & 90,5 & & & \\
\hline Total & 21 & 100,0 & 21 & 100,0 & & & \\
\hline
\end{tabular}


Tabel 5. Hubungan Cuci Tangan dengan Kejadian Diare Pada Balita Di Desa Sumbang Kecamatan Sumbang Kabupaten Banyumas Tahun 2016

\begin{tabular}{|c|c|c|c|c|c|c|c|}
\hline \multirow{3}{*}{ Cuci Tangan } & \multicolumn{4}{|c|}{ Kejadian Diare pada Balita } & \multirow{3}{*}{$\begin{array}{c}\text { Nilai } \\
\text { P }\end{array}$} & \multirow{3}{*}{ OR } & \multirow{3}{*}{$95 \% \mathrm{CI}$} \\
\hline & \multicolumn{2}{|c|}{ Diare } & \multirow{2}{*}{$\begin{array}{c}\text { Tidak } \\
\mathrm{n}\end{array}$} & \multirow{2}{*}{$\begin{array}{r}\text { Diare } \\
(\%) \\
\end{array}$} & & & \\
\hline & $\mathrm{n}$ & $(\%)$ & & & & & \\
\hline Tidak baik & 16 & 76,2 & 8 & 38,1 & & & \\
\hline Baik & 5 & 23,8 & 13 & 61,9 & 0,029 & 5,200 & $1,367-19,774$ \\
\hline Total & 21 & 100,0 & 21 & 100,0 & & & \\
\hline
\end{tabular}

Tabel 6. Hubungan Pembuangan Tinja dengan Kejadian Diare Pada Balita Di Desa Sumbang Kecamatan Sumbang Kabupaten Banyumas Tahun 2016

\begin{tabular}{|c|c|c|c|c|c|c|c|}
\hline \multirow{3}{*}{ Pembuangan Tinja } & \multicolumn{4}{|c|}{ Kejadian Diare pada Balita } & \multirow{3}{*}{$\begin{array}{c}\text { Nilai } \\
\mathrm{P}\end{array}$} & \multirow{3}{*}{ OR } & \multirow{3}{*}{$95 \% \mathrm{CI}$} \\
\hline & \multicolumn{2}{|c|}{ Diare } & \multicolumn{2}{|c|}{ Tidak Diare } & & & \\
\hline & $\mathrm{n}$ & $(\%)$ & $\mathrm{n}$ & $(\%)$ & & & \\
\hline Tidak baik & 17 & 81,0 & 8 & 38,1 & & & \\
\hline Baik & 4 & 19,0 & 13 & 61,9 & 0,012 & 6,906 & $1,702-28,026$ \\
\hline Total & 21 & 100 & 21 & 100 & & & \\
\hline
\end{tabular}

\section{Hubungan Sarana Air Bersih Dengan Kejadian Diare Pada Balita.}

Saran air bersih yang digunakan oleh responden semua adalah sumur gali. Berdasarkan hasil penelitian, pada kelompok balita diare yang menggunakan sarana air bersih tidak memenuhi syarat 76,2\% lebih banyak dibandingkan pada kelompok balita tidak diare 19\%. Hasil pengolahan data dengan uji statistik diperoleh nilai $p=0,001$ dimana $p<0,05$, berarti Ho ditolak. Hal ini menunjukan bahwa ada hubungan yang signifikan antara sarana air bersih dengan kejadian diare pada balita di desa Sumbang.

Hasil penelitian ini sama dengan penitian yang dilakukan Bhakti Rochman Tri Bintaro (2010) yang menyebutkan ada hubungan sumber air dengan kejadian diare pada balita $(\mathrm{p}=0.009)$. Hasil penelitian ini juga sesuai dengan teori yang meyatakan bahwa penyakit diare dapat ditularkan melalui air, maka penyediaan air bersih yang baik secara kuantitas dan kualitas mutlak diperlukan dalam memenuhi kebutuhan hidup sehari-hari termasuk untuk menjaga kebersihan diri dan lingkungan. Untuk mencegah terjadinya diare, penyediaan air bersih yang cukup disetiap rumah tangga harus tersedia (Kementerian Kesehatan, 2011, h.68).

Kondisi sarana air bersih yang tidak memenuhi syarat memiliki risiko terkena diare pada balita 13,6 kali (CI=3,09159,831) lebih besar dibandingkan sarana air bersih yang memenuhi syarat. Sarana air bersih yang digunakan oleh responden semuanya adalah sumur gali. Sebagian besar sumur gali yang tidak memenuhi syarat karena ada jamban dalam radius $<10 \mathrm{~m}$ dari sumur sebanyak 2,4\%, ada sumber pencemaran lain (kotoran hewan, sampah) dalam jarak radius $<10 \mathrm{~m}$ dari sumur sebanyak $47,6 \%$, pembuangan air yang buruk yang menyebabkan air tidak mengalir dalam jarak radius $<2 \mathrm{~m}$ dari sumur sebanyak 35,7\%, ada kerusakan pada saluran pembungan air 42,9\%, dinding sekeliling sumur retak atau terlalu rendah sebanyak 47,6\%, lebar lantai beton sekeliling sumur $<1 \mathrm{~m}$ sebanyak $51,7 \%$, ada bagian dinding sumur yang berada $3 \mathrm{~m}$ dibawah tanah yang tidak tertutup rapat sebanyak $66,7 \%$, ada retakan pada lantai beton disekeliling sumur sebanyak 59,5\%, tali dan ember diletakan dengan posisi yang memungkinkan akan kotor sebanyak 40,5\%.

Kondisi sumur gali yang tidak memenuhi syarat seperti rincian diatas dapat menyebabkan air sumur tercemar atau terkontaminasi kotoran sehingga dapat menjadi sumber penularan diare. Air sumur yang sudah tercemar apabila digunakan untuk keperluan sehari-hari seperti digunakan sebagai sumber air minum, mencuci bahan makanan dan peralatan makan/memasak tentunya akan memilliki risiko menyebabkan diare. Maka dari itu masyarakat sebaiknya memperbaiki kondisi fisik sumur gali dengan bangunan permanen, meliputi :

1) Dinding sumur minimal sedalam $3 \mathrm{~m}$ dari permukaan tanah, dibuat dari tembok yang tidak tembus air atau bahan kedap air untuk mencegah perembesan air yang telah tercemar kedalam sumur. Kedalaman $3 \mathrm{~m}$ diambil karena bakteri pada umumnya tidak dapat hidup lagi. 
2) Bibir sumur harus kedap air setinggi 1 meter dari permukaan tanah.

3) Lantai sumur harus kedap air, mempunyai lebar sekeliling sumur minimal 1 meter.

4) Adanya saluran pembuangan air limbah yang kedap air ke arah pengolahan air buangan atau peresapan.

\section{Hubungan Jamban Dengan Kejadian Diare Pada Balita}

Berdasarkan hasil penelitian, pada kelompok balita diare kepemilikan jamban tidak memenuhi syarat 76,2\% lebih tinggi dibandingkan pada kelompok balita tidak diare 33,3\%. Responden yang memilki jamban leher angsa sejumlah 19 rumah, sedangkan 23 responden tidak memiliki jamban dan menggunakan sungai sebagai sarana buang air besar.

Hasil pengolahan data dengan uji chi square diperoleh nilai $\mathrm{p}=0,013$ dimana $\mathrm{p}<$ 0.05 , berarti Ho ditolak. Hal ini menunjukan bahwa ada hubungan yang signifikan antara jamban dengan kejadian diare pada balita di desa Sumbang. Kondisi jamban yang tidak memenuhi syarat memiliki risiko terkena diare pada balita 6,4 kali (CI=1,654-24,770) lebih besar dibandingkan jamban yang memenuhi syarat. Hasil penelitian ini sama dengan penitian yang dilakukan oleh Bhakti Rochman Tri Bintaro (2010) yang menyebutkan ada hubungan antara jenis jamban dengan kejadian diare pada balita $(p=0,029)$. Hasil penelitian ini juga sesuai dengan teori yang menyatakan bahwa faktor risiko terjadinya diare adalah faktor lingkungan, faktor lingkungan yang

dominan adalah pembuangan tinja. (Departemen kesehatan, 2002, h.12).

Sebagai upaya mencegah terjadinya diare sebaiknya masyarakat menggunakan jamban leher angsa dengan septic tank untuk mencegah kontaminasi kotoran dengan badan air, mencegah tinja agar tidak dihinggapi lalat, dan mencegah bau tidak sedap Jamban leher angsa memilki keuntungan antara lain berbentuk leher angsa sehingga akan selalu terisi air, yang berfungsi sebagai sumbat sehingga bau dari jamban tidak tercium dan mencegah masuknya lalat kedalam lubang. Jamban ini juga dapat dibuat didalam rumah karena tidak minimbulkan bau. Jarak septic tank dengan sumur gali minimal $10 \mathrm{~m}$ untuk menghindari pencemaran terhadap sumur gali.

Melihat tingginya kasus diare di desa Sumbang dan akses jamban masih rendah $20,03 \%$, sedangkan mata pencaharian penduduk mayoritas adalah buruh harian lepas, untuk itu sebagai bahan masukan bagi pemerintah desa untuk mengalokasikan

anggaran pembangunan desa untuk pembuatan sarana jamban umum.

\section{Hubungan Penyimpanan Makanan Dengan Kejadian Diare}

Berdasarkan hasil penelitian, pada kelompok balita diare penyimpanan makanan yang tidak baik $85,7 \%$ lebih banyak dibandingkan pada kelompok balita tidak diare 42,9\%. Berdasakan hasil pengolahan data dengan uji chi square diperoleh nilai $p=0,010$ dimana $p<0,05$, berarti Ho ditolak. Hal ini menunjukan bahwa ada hubungan yang signifikan antara penyimpanan makanan dengan kejadian diare pada balita di desa Sumbang. Nilai Odd Ratio $\quad(\mathrm{OR})=8 \quad(\mathrm{CI}=1,790-35,744)$, menunjukan bahwa untuk penyimpanan makanan yang tidak baik memiliki risiko 8 kali lebih besar terkena diare pada balita dari pada penyimpanan makanan yang baik.

Tempat penyimpanan makanan berkaitan dengan kejadian diare, karena kuman penyebab diare biasanya menyebar melalui fecal oral antara lain melalui makanan/ minuman yang tercemar tinja atau kontak langsung dengan tinja penderita diare (Depkes, 2014, h.11).

Adapun syarat tempat penyimpanan makanan yang baik yaitu makanan disimpan pada tempat khusus untuk makanan, tertutup dan dalam kondisi yang bersih agar terlindung dari lalat, kecoa, dan tikus (Ditjen PPM \& PLP Depkes RI, 1997, h.27). Kondisi tempat penyimpanan makanan pada responden tidak baik yaitu makanan tidak disimpan pada tempat khusus untuk menyimpan makanan sebanyak 16,7\%, tempat penyimpanan makanan dalam kondisi tidak tertutup sebanyak 26,2\% dan tempat penyimpanan makanan dalam kondisi tidak bersih 59,5\%.

Kondisi tempat penyimpanan makanan yang tidak tertutup menyebabkan makanan tidak terlindung dari lalat, kecoa dan tikus. Tempat penyimpanan makanan yang kotor juga dapat mengkontaminasi

makanan yang disimpan sehingga menyebabkan makanan menjadi tercemar dan menyebabkan diare.

Sebagai salah satu upaya untuk mencegah diare, disarankan masyarakat menyimpan makanan dilemari khusus makanan yang tertutup dan apabila makanan diletakan diatas meja sebaiknya ditutup dengan tudung saji agar makanan tidak dihinggapi lalat. Kebersihan lemari 
penyimpanan makanan dan meja makan juga harus selalu dijaga.

\section{Hubungan Penyediaan Air Minum Dengan Kejadian Diare Pada Balita}

Persentase balita diare yang penyediaan air minumnya tidak baik $71,4 \%$ lebih tinggi dibandingkan pada kelompok balita tidak diare $8,5 \%$. Berdasarkan hasil pengolahan data dengan uji chi square diperoleh nilai $p=0,000$ dimana $p<0,05$, berarti Ho ditolak. Hal ini menunjukan bahwa ada hubungan yang signifikan antara penyediaan air minum dengan kejadian diare pada balita di desa Sumbang. Penyediaan air minum yang tidak baik akan memiliki risiko terkena diare pada balita 23,75 kali lebih besar dibandingkan dengan penyediaan air minum yang baik.

Air minum yang digunakan oleh responden semuanya telah dimasak sampai mendidih. Air minum yang direbus sampai mendidh akan mematikan mikroorganisme yang ada dalam air tersebut sehingga tidak menimbulkan penyakit. Namun masih ada responden yang menyimpan air minum dalam wadah terbuka sebanyak 2,4\% dan tempat penyimpanan air minum dalam kondisi tidak bersih 38,1\%. Tempat penyimpanan air minum yang terbuka dan kotor dapat menyebabkan air tercemar. Menggunakan air minum yang tercemar berisiko menyebabkan diare.

Sebagai upaya untuk mencegah diare, sebaiknya masyarakat menggunakan tempat penyimpanan minuman dalam wadah yang tertutup dan bersih. Adapun syarat penyimpanan air minum berdasarkan PERMENKES RI Nomor 3 Tahun 2014 tentang Sanitasi Total Berbasis Masyarakat, yaitu:

1. Wadah bertutup, berleher sempit, dan lebih baik dilengkapi dengan kran.

2. Air minum sebaiknya disimpan di wadah pengolahannya.

3. Air yang sudah diolah sebaiknya disimpan dalam tempat yang bersih dan selalu tertutup.

4. Minum air dengan menggunakan gelas yang bersih dan kering atau tidak minum air langsung mengenai mulut/ wadah kran.

5. Letakkan wadah penyimpanan air minum di tempat yang bersih dan sulit terjangkau oleh binatang.

6. Wadah air minum dicuci setelah tiga hari atau saat air habis.

\section{Hubungan Cuci Tangan Dengan Kejadian Diare Pada Balita}

Berdasarkan hasil penelitian, pada kelompok balita diare yang cuci tangan kategori tidak baik $76,2 \%$ lebih tinggi dibandingkan pada kelompok balita tidak diare $38,1 \%$. Hasil uji statistik hubungan antara cuci tangan dengan kejadian diare pada balita diperoleh nilai $p=0,029$ dimana $p<0,05$, berarti Ho ditolak. Hal ini menunjukan bahwa ada hubungan yang signifikan antara cuci tangan dengan kejadian diare pada balita di desa Sumbang. Cuci tangan yang tidak baik memiliki resiko terkena diare pada balita 5,2

kali (CI=1,367-19,774) lebih besar dibandingkan dengan cuci tangan yang baik.

Hasil penelitian ini sama dengan penitian yang dilakukan oleh Yulia Mega Agustina (2013) yang menyebutkan ada hubungan antara perilaku cuci tangan dengan kejadian diare pada balita $(p=0,001)$.

Sebagian responden belum cuci tangan dengan baik yaitu tangan balita/pengasuh tidak dicuci dengan sabun sebelum makan/menyuapi makanan sejumlah $54,8 \%$, tidak dicuci dengan air yang mengalir sejumlah 28,6\%, sedangkan yang tidak cuci tangan sesudah buang air besar dan buang air kecil sejumlah $14,3 \%$. Cuci tangan yang tidak baik dapat meningkatkan resiko terjadinya diare, untuk itu disarankan kepada masyarakat agar membiasakan diri cuci tangan pakai sabun (CTPS) dengan air mengalir sebelum makan dan sesudah buang air besar / buang air kecil. CTPS dapat menurunkan kejadian diare hingga 47\% (Kemenkes, 2011, hal 1). Hal ini penting diketahui masyarakat agar dapat meningkatkan kesadaran untuk praktik CTPS dalam kehidupan sehari-hari.

\section{Hubungan Pembuangan Tinja Dengan Kejadian Diare pada Balita}

Berdasarkan hasil penelitian, pada kelompok balita diare yang pembuangan tinjanya tidak baik $81 \%$ lebih tinggi dibandingkan pada kelompok balita tidak diare $38,1 \%$. Sedangkan pada kelompok balita tidak diare yang pembuangan tinjanya baik $61,9 \%$ lebih tinggi dibandingkan pada balita diare $19 \%$.

Hasil pengolahan data dengan uji chi square diperoleh nilai $p=0,012$ dimana $p \leq$ 0,05 , berarti H0 ditolak. Hal ini menunjukan bahwa ada hubungan yang signifikan antara pembuangan tinja dengan kejadian diare pada balita di desa Sumbang. Pembuangan tinja yang tidak baik memiliki risiko terkena diare pada balita 6,9 kali $(\mathrm{CI}=1,702-28,026)$ lebih besar dibandingkan pembuangan tinja yang

baik. Hasil penelitian ini sama dengan penitian yang dilakukan oleh Yulia Mega agustina (2013) yang menyatakan ada hubungan antara perilaku menggunakan 
jamban dengan kejadian diare pda balita $(p=0,002)$.

Jumlah responden yang pembuangan tinjanya baik yaitu di jamban leher angsa dengan septic tank sejumlah 17 responden, sedangkan yang pembuangan tinjanya tidak baik yaitu masing buang air besar di sungai sejumlah 25 responden. Pembuangan tinja yang tidak baik memiliki risiko terkena diare, karena itu disarankan kepada masyarakat agar buang air besar di jamban leher angsa dengan septic tank untuk mencegah kontaminasi kotoran dengan badan air, mencegah tinja agar tidak dihinggapi lalat, dan mencegah bau tidak sedap Jarak septic tank dengan sumur gali minimal $10 \mathrm{~m}$ untuk menghindari pencemaran terhadap sumur gali (PERMENKES RI Nomor 3 Tahun 2014 tentang Sanitasi Total Berbasis Masyarakat, 2014, h.13).

c. Pengaruh Sarana Air Bersih, Jamban, Penyimpanan Makanan, Penyediaan Air Minum, Cuci Tangan Dan Pembuangan Tinja Secara Bersama-Sama Terhadap Kejadian Diare Pada Balita

Tabel 9. Model Akhir Hasil Analisis Regresi Logistik

\begin{tabular}{|c|c|c|c|c|c|}
\hline No & Faktor & B & Nilai p & $\begin{array}{l}\text { Exp.B } \\
\text { (RP) }\end{array}$ & $95 \% \mathrm{CI}$ \\
\hline 1 & $\begin{array}{l}\text { Sarana air } \\
\text { bersih }\end{array}$ & 3,232 & 0,006 & 25,329 & $\begin{array}{l}0,560- \\
250,644\end{array}$ \\
\hline 2 & $\begin{array}{l}\text { Penyediaan } \\
\text { air minum }\end{array}$ & 3,761 & 0.002 & 42,975 & $\begin{array}{l}3,767- \\
490,318\end{array}$ \\
\hline \multicolumn{2}{|c|}{ Constan } & -4.068 & 0,002 & 0.017 & \\
\hline
\end{tabular}

Berdasarkan hasil analisis multivariat diketahui bahwa jamban, penyimpanan makananan, cuci tangan dan pembuangan tinja tidak berpengaruh secara bersama-sama terhadap kejadian diare pada balita karena nilai $p>0,05$. Variabel independen yang memiliki pengaruh secara bersama-sama terhadap kejadian diare pada balita di desa Sumbang yaitu sarana air bersih $(p=0,006)$ dan penyediaan air minum $(\mathrm{p}=0,002)$ dengan nilai $\mathrm{p}<0,05$ maka dinyatakan bermakna secara statistik atau ada pengaruh yang signifikan antara variabel independen yaitu sarana air bersih dan penyediaan air minum terhadap kejadian diare pada balita di desa Sumbang.

Hasil analisis multivariat juga menunjukkan bahwa faktor yang paling berpengaruh terhadap kejadian diare pada balita di desa Sumbang adalah penyediaan air minum dengan nilai Rasio Prevalensi (RP) sebesar 42,975 (CI=3,767-490,318).

\section{Simpulan Dan Saran}

a. Simpulan

1) Ada hubungan sarana air bersih dengan kejadian diare pada baita di desa Sumbang $(\mathrm{p}=0,001)$, dengan OR 13,6 $(\mathrm{CI}=3,091-59,831)$

2) Ada hubungan jamban dengan kejadian diare pada baita di desa Sumbang $(\mathrm{p}=0,013)$, dengan OR 6,4 (CI=1,65424,774)

3) Ada hubungan penyimpanan makanan dengan kejadian diare pada baita di desa Sumbang $(\mathrm{p}=0,01)$, dengan OR 8 $(\mathrm{CI}=1,790-35,744)$.

4) Ada hubungan penyeiaan air minum dengan kejadian diare pada baita di desa Sumbang $(\mathrm{p}=0,00)$, dengan OR 23,75 $(\mathrm{CI}=4,179-134,987)$

5) Ada hubungan cuci tangan dengan kejadian diare pada baita di desa Sumbang $(\mathrm{p}=0,029)$, dengan OR 5,2 $(\mathrm{CI}=1,367-19,774)$

6) Ada hubungan pembuangan tinja dengan kejadian diare pada baita di desa Sumbang $(\mathrm{p}=0,012)$, dengan OR 6,906 $(\mathrm{CI}=1,702-28,026)$

7) Ada pengaruh secara bersama-sama antara sarana air bersih $(\mathrm{p}=0,006)$ dan penyediaan air minum $(\mathrm{p}=0,002)$ terhadap kejadian diare pada balita di desa Sumbang.

8) Faktor yang paling berpengaruh terhadap kejadian diare pada balita di desa Sumbang adalah penyediaan air minum dengan nilai Rasio Prevalensi (RP) sebesar 42,975 (CI=3,767-490,318).

\section{b. Saran}

Bagi Masyarakat, untuk mencegah terjadinya diare pada balita :

1) Memperbaiki kondisi fisik sarana air bersih/sumur gali untuk mencegah terjadinya diare dengan membuat dinding sumur minimal sedalam $3 \mathrm{~m}$, bibir sumur setinggi 1 meter, lantai sekeliling sumur minimal 1 meter dan adanya saluran pembuangan air limbah yang kedap air ke arah pengolahan air buangan atau peresapan.

2) Menggunakan jamban leher angsa dengan septic tank sebagai sarana buang air besar.

3) Menyimpan makanan pada lemari khusus untuk makanan, tertutup dan dalam kondisi bersih agar terlindung dari lalat, kecoa dan tikus.

4) Penyediaan air minum menggunakan air bersih yang telah dimasak mendidih dan ditempatkan dalam wadah tertutup dan bersih. 
5) Membiasakan cuci tangan menggunakan sabun dengan air mengalir sebelum makan/menyuapi anak dan sesudah buang air besar/kecil.

Bagi Pemerintah

1) Meningkatkan promosi kesehatan mengenai pentingnya sarana air bersih, jamban,penyimpanan makanan, penyediaan air minum, cuci tangan dan pembuangan tinja dalam pencegahan diare.

2) Masukan bagi pemerintah desa untuk mengalokasikan anggaran pembangunan desa untuk membuat jamban umum.

\section{Daftar Pustaka}

Aris Santjaka, 2014, Aplikasi SPSS Untuk analisis Data Penelitian Kesehatan, Yogyakarta: Nuha Medika.

Bhakti Rochman Tri Bintaro, 2010, Skripsi Hubungan Antara Sanitasi Lingkungan Dengan Kejadian Diare Pada Balita Di Kabupaten Jatipuro Kabupaten Karanganyar, Surakarta: Universitas Muhamadiyah Surakarta.

Departemen Kesehatan RI, 2004, Panduan Konseling Bagi Petugas Klinik sanitasi Di Puskesmas, Jakarta: Departemen Kesehatan

Dinas Kesehatan Kabupaten Banyumas, 2015, Profil Kesehatan Kabupaten Banyumas 2014, Purwokerto: Dinas Kesehatan Kabupaten Banyumas

Indonesia, Peraturan Perundang-Undangan, 2002, Keputusan Menteri Kesehatan RI. No. 1216/MENKES/SK/XI/2001 Tentang Pedoman Pemberantasan Penyakit Diare, Jakarta: Departemen Kesehatan, Direktorat Jenderal Pemberantasan Penyakit Menular Dan Penyehatan Lingkungan (Ditjen. PPM \& PL).

Kementerian Kesehatan RI, 2011, Buku Saku Cuci Tangan Pakai Sabun Di Masyarakat, Jakarta : Kementerian Kesehatan RI.

, 2015, Profil Kesehatan Indonesia

2014, Jakarta : Kementerian Kesehatan RI. Badan Penelitian dan Pengembangan Kesehatan, 2013, Riset Kesehatan Dasar RISKESDAS 2013, Jakarta : Kementerian Kesehatan RI.

,. Direktorat Jenderal Pengendalian Penyakit Dan Penyehatan Lingkungan (Ditjen. PP \& PL), 2011a, Buku Pedoman Pengendalian Penyakit Diare, Jakarta: Ditjen PP \& PL 2011b, Panduan Sistem Surveilans Air

Minum Dan sanitasi, Jakarta: Ditjen. PP \& PL ,2011c, Panduan Sosialisasi Tatalaksana Diare Pada Balita, Jakarta: Ditjen. PP \& PL. , 2014d, Peraturan Menteri Kesehatan R.I. Nomor 3 Tahun 2014 Tentang Sanitasi Total Berbasis Masyarakat, Jakarta: Kemenkes

Pemerintah Desa Sumbang, 2016, Profil Desa Sumbang Tahun 2016, Sumbang: Pemerintah Desa Sumbang.

Puskesmas 1 Sumbang, 2014, Profil Kesehatan Puskesmas 1 Sumbang 2013, Purwokerto: Puskesmas 1 Sumbang , 2015, Profil Kesehatan Puskesmas 1 Sumbang 2014, Purwokerto: Puskesmas 1 Sumbang , 2016, Profil Kesehatan Puskesmas 1 Sumbang 2015, Purwokerto: Puskesmas 1 Sumbang

Sayekti Budi Utama, 2011, Teknik Pengumpulan dan Pengolahan Data, Yogyakarta

Sinta Sasika Novel, 2011, Ensiklopedia Penyakit Menular dan Infeksi, Yogyakarta: Familia Pustaka Keluarga.

Soeparman, soeparmin, 2001, Pembuangan Tinja \& Limbah Cair Suatu Pengantar, Jakarta: EGCIlmu Perilaku, Jakarta: Rineka Cipta

Soekitdjo Notoatmodjo, 2007, Promosi Kesehatan .\& Ilmu Perilaku, Jakarata: Rineka Cipta

Sutanto Prio Hastono, 2001, Analisis Data, Jakarta: Universitas Indonesia

Water And Sanitation Program East asia And The Pacifik (WSP-EAP), 2011, Informasi Pilihan Jamban, Jakarta: Program PAMSIMAS Komponen B

Widoyono, 2008, Penyakit Tropis Epidemiologi Penularan Pencegahan \& Pemberantasannya, Jakarta: Erlangga.

Yulia Mega Agustina, 2013, Naskah Publikasi Hubungan Antara Perilaku Hidup Bersih Dan Sehat .(PHBS) Dengan Kejadian Diare Pada Balita Di Posyandu Dusun Ketangi Desa Banyusuco Kecamatan Playen Kabupaten Gunungkidul Yogyakarta, Yogyakarta: Sekolah Tinggi Ilmu Kesehatan 'Aisyiyah Yogyakarta. 